\title{
Hypoglycemic Therapy in Chronic Hepatic Disease Literature Review
}

\author{
Pedro Luis Imbeth-Acosta1 ${ }^{(1)}$, Nehomar Pájaro-Galvis ${ }^{2 *}\left(\mathbb{C}\right.$, Víctor Leal-Martinez ${ }^{3}(\mathbb{C}$, \\ Jorge Rico-Fontalvo ${ }^{4}\left(\mathbb{D}\right.$, Rodrigo Daza-Arnedo ${ }^{5}$ (), Orlando Castañeda-López ${ }^{6}(\mathbb{1}$, \\ María Cardona-Blanco $^{7}$ (), Karen Mercado-Anillos ${ }^{1}$, José Lucas-Daza9 ${ }^{9}$ (), \\ Christian Perez-Calvo ${ }^{10}{ }^{\circledR}$, Jhonatan Hernández-Meza11 ${ }^{(0)}$, Álvaro Barraza-Pombo12 $(\mathbb{1}$, \\ Marianela Florez-Ortega ${ }^{13}$ (), Jorge Hoyos-Fortich ${ }^{14}$ (), Isabella Uparella-Gulfo ${ }^{11}$ ()
}

${ }^{1}$ Blas de Lezo Clinic, Cartagena, Bolívar, Colombia

${ }^{2}$ Faculty of Health Sciences, University of Sinú, Cartagena, Bolívar, Colombia

${ }^{3}$ New Bocagrande Hospital, Cartagena, Bolívar, Colombia

${ }^{4}$ Colombian Association of Nephrology, Medellín, Colombia

${ }^{5}$ Colombian Association of Nephrology, Cartagena, Colombia

${ }^{6}$ Endocrinos SAS, Cartagena, Colombia

${ }^{7}$ Renal Unit B. Braun, Medellín, Antioquia, Colombia

${ }^{8}$ University of Cartagena, Cartagena, Bolívar, Colombia

${ }^{9}$ Colombian Association of Nephrology, Ibagué, Colombia

${ }^{10}$ Caribbean University Hospital, Cartagena, Colombia

${ }^{11}$ University of Sinu, Cartagena, Colombia

${ }^{12}$ Epidemiologist, Blas de Lezo Clinic, Cartagena, Colombia

${ }^{13}$ Naval Hospital, Cartagena, Colombia

${ }^{14}$ Rafael Nuñez University, Cartagena, Colombia

Email: drplia@yahoo.com, ^neho94@hotmail.com,victhork@hotmail.com,jorgericof@yahoo.com, rodrigoandres_2@hotmail.com, orlcas@gmail.com, mariaximenacarmonablanco@hotmail.com,drlucasdaza@gmail.com, ksofiama@gmail.com, christianperez05@hotmail.com, Jonathan234561@hotmail.com, barraza8104@hotmail.com, Marianelaflorezortega@hotmail.com, jorgehoyosfortich@gmail.com, isauparella@msn.com

How to cite this paper: Imbeth-Acosta, P.L., Pájaro-Galvis, N., Leal-Martinez, L., RicoFontalvo, J., Daza-Arnedo, R., CastañedaLópez, O., Cardona-Blanco, M., MercadoAnillo, K., Lucas-Daza, J., Perez-Calvo, C., Hernández-Meza, J., Barraza-Pombo, A., Florez-Ortega, M., Hoyos-Fortich, J. and Uparella-Gulfo, I. (2020) Hypoglycemic Therapy in Chronic Hepatic Disease Literature Review. Open Journal of Endocrine and Metabolic Diseases, 10, 137-146. https://doi.org/10.4236/ojemd.2020.1010013

Received: August 6, 2020

Accepted: October 26, 2020

Published: October 29, 2020

\begin{abstract}
Chronic liver disease (CLD) refers to a structural and functional change of the liver, which modifies the pharmacokinetics of multiple drugs, including hypoglycemic agents. This alteration depends on the severity degree of the liver disease, clinical characteristics of the patient, and comorbidities presence such as kidney disease and drug biochemistry. Insulin is considered a safe therapeutic strategy in patients with CLD, however, for many oral hypoglycemic agents, its use and dose adjustment will depend on the Child-Pugh score, based on the risk of hypoglycemia in this type of patient.
\end{abstract}

\section{Keywords}

Cirrhosis, Hypoglycemic Agents, Pharmacokinetics (MeSH) 
Copyright $\odot 2020$ by author(s) and Scientific Research Publishing Inc. This work is licensed under the Creative Commons Attribution International License (CC BY-NC 4.0). http://creativecommons.org/licenses/by-nc/ $\underline{4.0}$

\section{c) (i) Open Access}

\section{Effects of Chronic Liver Disease on Pharmacokinetics}

The structural and functional change of the liver in chronic liver disease (CLD) can generate hemodynamic and metabolic disorders that alter the pharmacokinetics of the drugs; this will depend on the characteristics of the patient (comorbidities, nutritional status), the severity of the CLD, and chemical characteristics of the drug [1] [2].

Multiple risk factors for adverse drug reactions are described in patients with CLD [3], such as:

- Decreased portal blood flow or increased resistance of the hepatic artery [4].

- Portosystemic shunt: avoids the liver's first-pass effect. Cardiotoxic drugs are not metabolized in the liver and cause changes in the heart rhythm [5] [6].

- Changes in cytochrome P450 activity [7].

- Cholestasis: serum drug levels may be increased due to inadequate bile secretion [3].

- Hypoalbuminemia: changes in fluid dynamics with retention in interstitial space [8]. In drugs with a high degree of albumin binding, it occurs with an increase of the plasma free level [9].

- Portal hypertension: Secondary complications such as ascites (change in volume of distribution), portal gastropathy (decreased absorption), and impaired renal blood flow (reduced renal clearance) [10].

\section{Diabetes and Chronic Liver Disease}

The liver is one of the main targets of insulin and counter-regulatory hormones, such as glucagon. A direct association between diabetes mellitus and the development of non-alcoholic fatty liver disease (NAFLD) was established, as shown in Figure 1 [11]. The prevalence of diabetes mellitus in patients with NAFLD and non-alcoholic steatohepatitis (non-alcoholic steatohepatitis NASH) is very high, reporting figures of up to $22.51 \%$ and $43.63 \%$ respectively; compared to the general population with a prevalence of $8.5 \%$ [12]. As a result of type 2 diabetes mellitus is being considered one of the risk factors most strongly related to the progression from NAFLD to NASH and cirrhosis [13], increasing the probability of developing NASH 2 - 3 times to non-diabetic patients [14]. Studies based on liver histology find that a proportion of patients with type 2 diabetes mellitus exhibits NASH up to $80 \%$ and advanced fibrosis of $30 \%$ - 40\% [15] [16] [17] [18].

\section{Pathophysiology between Diabetes Mellitus and Chronic Liver Disease}

Due to peripheral insulin resistance, the release of free fatty acids from adipose tissue increased [19], and so the absorption of fats by hepatocytes [20]. Initially, this accumulation of lipids in the liver works as a compensatory mechanism against lipotoxicity mediated by the increase in free fatty acids; however, as a consequence of the accumulation of intracellular triglycerides [21] the inflammatory 


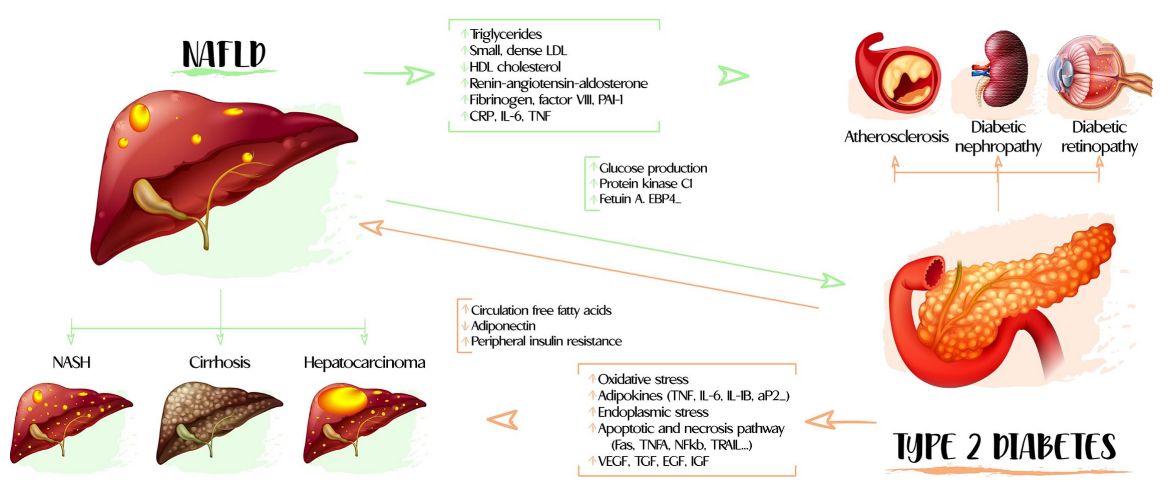

Figure 1. Pathophysiology of the connection between NAFLD, NASH and diabetes mellitus. Adapted from: Xia M-F, Bian H and Gao X (2019) NAFLD and Diabetes: Two Sides of the Same Coin? Rationale for Gene-Based Personalized NAFLD Treatment.

mediators MCP-1, IL-6, TNF $\alpha$, IL- $1 \beta$ [22] are expressed, activating the Kupffer cells [22], which results in the death of the hepatocyte due to apoptosis and necrosis [23]. The hepatic influence of cholesterol, lysophosphatidylcholine, and other lipid substances perpetuate the inflammatory state and lead to the formation of fibrosis [24]. As a result, a continuum of liver damage progression is generated, passing from NAFLD to NASH, cirrhosis, and finally, hepatocarcinoma [11].

\section{Treatment for Diabetes in Patients with Chronic Liver Disease}

Considering the pharmacokinetic alterations that hypoglycemic drugs can undergo in CLD, next will listed indications, contraindications, and dose adjustment of this group of patients.

\subsection{Insulin}

It is considered a safe treatment strategy in chronic liver disease. No dose adjustment is required regardless of cirrhosis severity [25] [26] [27]. Insulin requirements may vary. In patients with compensated cirrhosis, the requirements may be higher, since insulin resistance predominates in these, whereas in patients with decompensated cirrhosis, the hepatic insulin metabolism is severely impaired. Insulin should be used preferably with the hospitalized patient with close monitoring of blood glucose levels due to the risk of hypoglycemia [28].

\subsection{Metformin}

Metformin is the first-line therapy for patients with type 2 diabetes mellitus [29]. It does not undergo hepatic metabolism and is excreted unchanged by tubular secretion and glomerular filtration; however, chronic liver disease can be a risk factor to develop type B lactic acidosis [30]. The use of metformin has not been associated with the formation or exacerbation of liver injury, and may even be beneficial in patients with NAFLD, because a protective effect has been demonstrated for the development of hepatocarcinoma [31]. 
Due to case reports of type B lactic acidosis [32], the use of metformin exercise with caution on patients with moderate CLD and to avoid it on severe CLD patients. The Canadian Diabetes Association (CDA) recommends using clinical practice guidelines to avoid metformin in patients with hepatic failure [33] just as the American Diabetes Association (ADA) restricts the use of metformin in patients with severe liver disease [29].

It is suggested not to use metformin doses higher than $1500 \mathrm{mg}$ per day in patients with chronic liver disease [30].

\subsection{Sulfonylureas}

Sulfonylureas (SU) are alternative treatments to metformin on patients with type 2 diabetes mellitus. The first-generation is currently in disuse. Those of the second generation (glyburide/glibenclamide, glipizide, gliclazide) and third-generation (glimepiride), are classified by the guide of the American Diabetes Association (ADA), as second-line treatments in well-selected patients: no comorbidities and low-risk hypoglycemia [29]. All metabolized in the liver [30], have high plasma protein binding and are excreted through the kidneys [34] [35] [36] [37]. Due to this, there is an increased risk of hypoglycemia due to a lack of inactivation of the SU.

Clinical practice guidelines recommend using SU with caution and at low doses in patients with Child-Pugh A and B class cirrhosis. Avoid its use in patients with Child-Pugh C [30].

\subsection{Thiazolidinediones (TZD)}

It is metabolized by hydroxylation and oxidation. Its excretion is through bile and feces. The main side effect associated with this group of drugs is peripheral edema. Pioglitazone could be beneficial in the setting of patients with NAFLD and NASH. Histological improvement and ALT and AST levels were showed in a clinical trial compared to placebo $\mathrm{P}<0.001$ [38].

It is recommended to avoid TZD use in patients with elevated transaminases (ALT $>$ three times the upper limit of normal). Restrict the use of pioglitazone in patients with Child-Pugh B-C or peripheral edema [30].

\subsection{Dipeptidyl Peptidase-IV Inhibitors (DPP-4 Inhibitors)}

Sitagliptin and vildagliptin are excreted mostly through the kidneys or hydrolysis in multiple tissues without modification, respectively [39] [40]. For linagliptin, $80 \%$ of the administered dose is eliminated through enterohepatic recycling. Saxagliptin is metabolized mainly by hepatic cytochrome CYP3A4/5 and eliminated through the kidneys and the liver [39]. Compare with healthy controls, patients with a Child-Pugh score of 7 to 9 were included in a study to assess the pharmacokinetics of sitagliptin. An increase in the maximum serum concentration was found on patients with chronic liver disease, but it was not statistically significant [41]. Another case-control study evaluated the efficacy and safety of 
sitagliptin on patients with diabetes and chronic liver disease secondary to infection with the hepatitis $\mathrm{C}$ virus (HCV). There were no significant changes in AST and ALT levels during the 48-week follow-up in the sitagliptin and control groups [42]. In a safety meta-analysis, consisting of 38 phase II and III clinical trials, patients treated with vildagliptin were found to have mild elevations in liver enzymes compared to controls. In two of the patients, a marked elevation of transaminases (ALT-AST $>$ ten times the upper limit of normal) and bilirubins ( $>2$ times ULN) was evident [43] [44]. Clinical practice guidelines recommend DPP-4 inhibitors be used safely in patients with Child-Pugh A class cirrhosis without a dose adjustment requirement (except for vildagliptin). In Child-Pugh $B$ class patients, use with caution, and in Child-Pugh C class patients should be avoided [30].

\subsection{Sodium-Glucose 2 (iSGLT2) Co-Transporter Inhibitors}

The pharmacokinetics of SGLT2 inhibitors (Canagliflozin, Dapagliflozin, and Empagliflozin) are similar. They have a long half-life, which allows the administration once a day. Its metabolism is hepatic, and it is excreted by the kidneys [45]. The serum concentration of canagliflozin is not affected in patients with chronic liver disease [46]. Dapagliflozin decreases its maximum serum concentration in patients with CLD, even in mild forms [47].

In a safety meta-analysis with all SGLT2 inhibitors composed of phase II and III clinical trials, no hepatotoxicity mediated by these drugs was observed [48] [49] [50]. The current recommendation is to safely use iSGLT2 in patients with Child-Pugh A class liver cirrhosis, administer with caution in Child-Pugh B class patients and restrict them in Child-Pugh $\mathrm{C}$ class patients. Patients with a high risk of dehydration and arterial hypotension should be closely monitored. [30].

\subsection{GLP1 Analogues}

Renal mechanisms predominantly eliminate exenatide. Liraglutide and dulaglutide are broken down by protein catabolism. Nevertheless, liver metabolism is not an important route of elimination for these drugs. There are no clinical trials of exenatide pharmacokinetics in CLD [30]. However, reductions in ALT levels have been demonstrated in patients using said GLP1 analog [51].

The serum concentration of Liraglutide decreases in patients with CHD; however, this is not a negative outcome in clinical outcomes. In contrast, the use of Liraglutide improved diabetes mellitus and decreased inflammation and liver fibrosis and promoted bodyweight reduction [52].

All GLP1 analogs can be used in patients with Child-Pugh A class liver cirrhosis without dose adjustment requirement. In Child-Pugh B class patients, they should be used with caution, and in the case of Child-Pugh $\mathrm{C}$ class patients, their administration is not recommended [30].

\section{Conclusions}

Despite the accumulation of recent information regarding the negative impact of 
diabetes mellitus on the survival of cirrhotic patients, to date, very few therapeutic studies have been published with the aim of knowing which are the most appropriate treatment regimens for diabetes and, above all, to find out what is the impact of treatment on patient survival. Furthermore, treatment of the patient with cirrhosis is difficult due to the following: 1) around half of the patients have malnutrition; 2) when DM is diagnosed, the patient has advanced liver failure; 3) the majority of oral hypoglycemic drugs and insulin are metabolized in the liver; 4) these patients frequently have hypoglycemic episodes; 5) adherence to treatment is possibly low, particularly in alcoholics, and 6) persistence of alcohol intake [53].

The initial treatment of patients with mild to moderate hyperglycemia and compensated liver disease could be a change in lifestyle, since at this stage insulin resistance is a predominant factor. However, these therapeutic measures can be compromised by very restrictive diets that could aggravate the state of malnutrition. Exercise, which improves insulin resistance, is not appropriate in patients with active liver disease [54]. In advanced stages of CLD, when diabetes mellitus manifests clinically, the use of oral hypoglycemic agents may be necessary. However, most of these drugs are metabolized in the liver, so monitoring of blood glucose levels during treatment should be close to avoid hypoglycemia [55].

Metformin is the first-line drug in type 2 diabetes mellitus since it decreases insulin resistance. However, this drug is relatively contraindicated in patients with advanced liver failure and in those who continue alcohol intake due to the risk of type B lactic acidosis.

All are metabolized in the liver, have high plasma protein binding and are excreted via the kidneys. Due to the increased risk of hypoglycemia due to lack of inactivation of the SU, clinical practice guidelines recommend: use the SU with caution and at low doses in patients with liver cirrhosis class CHILD PUGH A and B. Avoid its use in patients with CHILD PUGH C.

Thiazolidinediones can be especially helpful as they increase insulin sensitivity. Apparently safer, rosiglitazone and pioglitazone are not recommended if there is evidence of active liver disease or if ALT levels are above 3 times the normal value.

Finally, liver transplantation quickly normalizes glucose tolerance and insulin sensitivity. This effect is thought to be due to improved hepatic clearance and peripheral glucose disposition. This last effect could be secondary to a correction of chronic hyperinsulinemia. However, liver transplantation cures hepatogenic only in $67 \%$ of cases. Diabetes was not corrected in $33 \%$ due to the persistence of reduced pancreatic beta cell function [56].

\section{Conflicts of Interest}

The authors declare no conflicts of interest regarding the publication of this paper.

\section{References}

[1] Westphal, J.F. and Brogard, J.M. (1997) Drug Administration in Chronic Liver Dis- 
ease. Drug Safety, 17, 47-73. https://doi.org/10.2165/00002018-199717010-00004

[2] Franz, C.C., Hildbrand, C., Born, C., Egger, S., Rätz Bravo, A.E. and Krähenbühl, S. (2013) Dose Adjustment in Patients with Liver Cirrhosis: Impact on Adverse Drug Reactions and Hospitalizations. European Journal of Clinical Pharmacology, 69, 1565-1573. https://doi.org/10.1007/s00228-013-1502-Z

[3] Lewis, J.H. and Stine, J.G. (2013) Review Article: Prescribing Medications in Patients with Cirrhosis-A Practical Guide. Alimentary Pharmacology \& Therapeutics, 37, 1132-1156. https://doi.org/10.1111/apt.12324

[4] Edginton, A.N. and Willmann, S. (2008) Physiology-Based Simulations of a Pathological Condition: Prediction of Pharmacokinetics in Patients with Liver Cirrhosis. Clinical Pharmacokinetics, 47, 743-752.

https://doi.org/10.2165/00003088-200847110-00005

[5] Trevisani, F., Merli, M., Savelli, F., Valeriano, V., Zambruni, A., Riggio, O., et al. (2003) QT Interval in Patients with Non-Cirrhotic Portal Hypertension and Cirrhotic Patients Treated with a Transjugular Intrahepatic Portosystemic Shunt. Journal of Hepatology, 38, 461-467. https://doi.org/10.1016/S0168-8278(03)00057-6

[6] Bal, J.S. and Thuluvath, P.J. (2003) Prolongation of QTc Interval: Relationship with Etiology and Severity of the Liver Disease, Mortality, and Liver Transplantation. Liver International: Official Journal of the International Association for the Study of the Liver, 23, 243-248. https://doi.org/10.1034/j.1600-0676.2003.00833.x

[7] Frye, R.F., Zgheib, N.K., Matzke, G.R., Chaves-Gnecco, D., Rabinovitz, M., Shaikh, O.S., et al. (2006) Liver Disease Selectively Modulates Cytochrome P450-Mediated Metabolism. Clinical Pharmacology \& Therapeutics, 80, 235-245.

https://doi.org/10.1016/j.clpt.2006.05.006

[8] Garcia-Martinez, R., Caraceni, P., Bernardi, M., Gines, P., Arroyo, V. and Jalan, R. (2013) Albumin: The Pathophysiologic Basis of Its Role in the Treatment of Cirrhosis and Its Complications. Hepatology (Baltimore, Md.), 58, 1836-1846. https://doi.org/10.1002/hep.26338

[9] Ulldemolins, M., Roberts, J.A., Rello, J., Paterson, D.L. and Lipman, J. (2011) The Effects of Hypoalbuminemia on Optimizing Antibacterial Dosing in Critically Ill Patients. Clinical Pharmacokinetics, 50, 99-110. https://doi.org/10.2165/11539220-000000000-00000

[10] Delcò, F., Tchambaz, L., Schlienger, R., Drewe, J. and Krähenbühl, S. (2005) Dose Adjustment in Patients with Liver Disease. Drug Safety, 28, 529-545. https://doi.org/10.2165/00002018-200528060-00005

[11] Xia, M.-F., Bian, H. and Gao, X. (2019) NAFLD, and Diabetes: Two Sides of the Same Coin? The Rationale for Gene-Based Personalized NAFLD Treatment. Frontiers in Pharmacology, 10, 877. https://doi.org/10.3389/fphar.2019.00877

[12] Younossi, Z.M., Koenig, A.B., Abdelatif, D., Fazel, Y., Henry, L. and Wymer, M. (2016) Global Epidemiology of Non-Alcoholic Fatty Liver Disease-Meta-Analytic Assessment of Prevalence, Incidence, and Outcomes. Hepatology, 64, 73-84. https://doi.org/10.1002/hep.28431

[13] Adams, L.A., Lymp, J.F., St Sauver, J., Sanderson, S.O., Lindor, K.D., Feldstein, A. et al. (2005) The Natural History of Non-Alcoholic Fatty Liver Disease: A Population-Based Cohort Study. Gastroenterology, 129, 113-121. https://doi.org/10.1053/j.gastro.2005.04.014

[14] Portillo-Sanchez, P., Bril, F., Maximos, M., Lomonaco, R., Biemacki, D., Orsak, B., et al. (2015) High Prevalence of Nonalcoholic Fatty Liver Disease in Patients with Type 2 Diabetes Mellitus and Normal Plasma Aminotransferase Levels. The Journal 
of Clinical Endocrinology and Metabolism, 100, 2231-2238.

https://doi.org/10.1210/jc.2015-1966

[15] Bazick, J., Donithan, M., Neuschwander-Tetri, B.A., Kleiner, D., Brunt, E.M., Wilson, L., et al. (2015) Clinical Model for NASH and Advanced Fibrosis in Adult Patients with Diabetes and NAFLD: Guidelines for Referral in NAFLD. Diabetes Care, 38, 1347-1355. https://doi.org/10.2337/dc14-1239

[16] Tian, J., Goldstein, J.L. and Brown, M.S. (2016) Insulin Induction of SREBP-1c in Rodent Liver Requires LXR $\alpha$-C/EBP $\beta$ Complex. Proceedings of the National Academy of Sciences of the United States of America, 113, 8182-8187. https://doi.org/10.1073/pnas.1608987113

[17] Schmid, A.I., Szendroedi, J., Chmelik, M., Krssak, M., Moser, E. and Roden, M. (2011) Liver ATP Synthesis Is Lower and Relates to Insulin Sensitivity in Patients with Type 2 Diabetes. Diabetes Care, 34, 448-453. https://doi.org/10.2337/dc10-1076

[18] Kamagate, A. and Dong, H.H. (2008) FoxO1 Integrates Insulin Signaling to VLDL Production. Cell Cycle, 7, 3162-3170. https://doi.org/10.4161/cc.7.20.6882

[19] Kim, D.S., Jackson, A.U., Li, Y.K., Stringham, H.M., Kuusisto, J., Kangas, A.J., et al. (2017) Novel Association of TM6SF2 rs58542926 Genotype with Increased Serum Tyrosine Levels and Decreased apoB-100 Particles in Finns. Journal of Lipid Research, 58, 1471-1481. https://doi.org/10.1194/jlr.P076034

[20] Miquilena-Colina, M.E., Lima-Cabello, E., Sanchez-Campos, S., García-Mediavilla, M.V., Fernández-Bermejo, M., Lozano-Rodríguez, T., et al. (2011) Hepatic Fatty Acid Translocase CD36 Upregulation Is Associated with Insulin Resistance, Hyperinsulinaemia and Increased Steatosis in Non-Alcoholic Steatohepatitis and Chronic Hepatitis C. Gut, 60, 1394-1402. https://doi.org/10.1136/gut.2010.222844

[21] Sharma, M., Mitnala, S., Vishnubhotla, R.K., Mukherjee, R., Reddy, D.N. and Rao, P.N. (2015) The Riddle of Non-Alcoholic Fatty Liver Disease: Progression from Non-Alcoholic Fatty Liver to Non-Alcoholic Steatohepatitis. Journal of Clinical and Experimental Hepatology, 5, 147-158. https://doi.org/10.1016/j.jceh.2015.02.002

[22] DI Maira, G., Pastore, M. and Marra, F. (2018) Liver Fibrosis in the Context of Non-Alcoholic Steatohepatitis: The Role of Adipokines. Minerva Gastroenterologica e Dietologica, 64, 39-50.

[23] Kazankov, K., Jørgensen, S.M.D., Thomsen, K.L., Møller, H.J., Vilstrup, H., George, J., et al. (2019) The Role of Macrophages in Non-Alcoholic Fatty Liver Disease and Non-Alcoholic Steatohepatitis. Nature Reviews Gastroenterology \& Hepatology, 16, 145-159. https://doi.org/10.1038/s41575-018-0082-X

[24] Luedde, T., Kaplowitz, N. and Schwabe, R.F. (2014) Cell Death and Cell Death Responses in Liver Disease: Mechanisms and Clinical Relevance. Gastroenterology, 147, 765-783.e4. https://doi.org/10.1053/j.gastro.2014.07.018

[25] Elkrief, L., Rautou, P.-E., Sarin, S., Valla, D., Paradis, V. and Moreau, R. (2016) Diabetes Mellitus in Patients with Cirrhosis: Clinical Implications and Management. Liver International: Official Journal of the International Association for the Study of the Liver, 36, 936-948. https://doi.org/10.1111/liv.13115

[26] Garcia-Compean, D., Jaquez-Quintana, J.O., Gonzalez-Gonzalez, J.A. and Maldonado-Garza, H. (2009) Liver Cirrhosis and Diabetes: Risk Factors, Pathophysiology, Clinical Implications, and Management. World Journal of Gastroenterology, 15, 280-288. https://doi.org/10.3748/wig.15.280

[27] Gangopadhyay, K.K. and Singh, P. (2017) Consensus Statement on Dose Modifications of Antidiabetic Agents in Patients with Hepatic Impairment. Indian Journal of Endocrinology and Metabolism, 21, 341-354. 
https://doi.org/10.4103/ijem.IJEM 51216

[28] Petrides, A.S. (1994) Liver Disease and Diabetes Mellitus. Diabetes Reviews, 2, 2-18.

[29] American Diabetes Association (2019) 9. Pharmacologic Approaches to Glycemic Treatment: Standards of Medical Care in Diabetes 2019. Diabetes Care, 42, S90-102. https://doi.org/10.2337/dc19-S009

[30] Hamed, A.E., Abas, B., Shaltout, I., Esmt, G. and Gomez, R. (2015) Managing Diabetes and Liver Disease Association, Guidelines (Consensus) Development. Journal of Endocrinology, Diabetes \& Obesity, 3, 1073.

[31] Scheen, A.J. (2014) Pharmacokinetic and Toxicological Considerations for the Treatment of Diabetes in Patients with Liver Disease. Expert Opinion on Drug Metabolism \& Toxicology, 10, 839-857. https://doi.org/10.1517/17425255.2014.902444

[32] Brackett, C.C. (2010) Clarifying Metformin's Role and Risks in Liver Dysfunction. Journal of the American Pharmacists Association, 50, 407-410. https://doi.org/10.1331/JAPhA.2010.08090

[33] Canadian Diabetes Association (2016) Antihyperglycemic Agents for Use in Type 2 Diabetes. https://guidelines.diabetes.ca/Browse/Chapter13

[34] Gliclazide Tablets, Prescribing Information. Actavis UK Ltd., Barnstaple. https://www.medicines.org.uk/emc/product/5883/smpc\#gref

[35] (2013) Diaßeta (Glyburide) Tablet, Prescribing Information. Sanofi, Bridgewater. http://www.accessdata.fda.gov/drugsatfda docs/label/2013/017532Orig1s034lbl.pdf

[36] (2013) Amaryl (Glimepiride) Tablet, Prescribing Information. Sanofi, Bridgewater. http://www.accessdata.fda.gov/drugsatfda docs/label/2013/020496s027lbl.pdf

[37] (2013) Glucotrol (Glipizide) Tablet, Prescribing Information. Pfizer Inc., New York. http://www.accessdata.fda.gov/drugsatfda docs/label/2013/017783s025lbl.pdf

[38] Chang, E., Park, C.Y. and Park, S.W. (2013) Role of Thiazolidinediones, Insulin Sensitizers, in Non-Alcoholic Fatty Liver Disease. Journal of Diabetes Investigation, 4, 517-524. https://doi.org/10.1111/jdi.12107

[39] Golightly, L.K., Drayna, C.C. and McDermott, M.T. (2012) Comparative Clinical Pharmacokinetics of Dipeptidyl Peptidase-4 Inhibitors. Clinical Pharmacokinetics, 51, 501-514. https://doi.org/10.1007/BF03261927

[40] The, Y.L. (2012) Clinical Pharmacokinetics and Pharmacodynamics of Vildagliptin. Clinical Pharmacokinetics, 51, 147-162. https://doi.org/10.2165/11598080-000000000-00000

[41] Migoya, E.M., Stevens, C.H., Bergman, A.J., Luo, W.L., Lasseter, K.C., Dilzer, S.C., et al. (2009) Effect of Moderate Hepatic Insufficiency on the Pharmacokinetics of Sitagliptin. Canadian Journal of Clinical Pharmacology, 16, e165-e170.

[42] Arase, Y., Suzuki, F., Kobayashi, M., Suzuki, Y., Kawamura, Y., Matsumoto, N., et al. (2011) Efficacy and Safety in Sitagliptin Therapy for Diabetes Complicated by Chronic Liver Disease Caused by Hepatitis C Virus. Hepatology Research, 41, 524529. https://doi.org/10.1111/j.1872-034X.2011.00798.x

[43] Ligueros-Saylan, M., Foley, J.E., Schweizer, A., Couturier, A. and Kothny, W. (2010) An Assessment of Adverse Effects of Vildagliptin versus Comparators on the Liver, the Pancreas, the Immune System, the Skin and in Patients with Impaired Renal Function from a Large Pooled Database of Phase II and III Clinical Trials. Diabetes, Obesity and Metabolism, 12, 495-509. https://doi.org/10.1111/j.1463-1326.2010.01214.x

[44] Kalra, S. (2011) Emerging Role of Dipeptidyl Peptidase-IV (DPP-4) Inhibitor Vildagliptin in the Management of Type 2 Diabetes. Journal of the Association of Phy- 
sicians of India, 59, 237-245.

[45] Scheen, A.J. (2015) Pharmacokinetics, Pharmacodynamics, and Clinical Use of SGLT2 Inhibitors in Patients with Type 2 Diabetes Mellitus and Chronic Kidney Disease. Clinical Pharmacokinetics, 54, 691-708.

https://doi.org/10.1007/s40262-015-0264-4

[46] Devineni, D., Curtin, C.R., Marbury, T.C., Smith, W., Vaccaro, N., Wexler, D., et al. (2015) Effect of Hepatic or Renal Impairment on the Pharmacokinetics of Canagliflozin, a Sodium-Glucose Co-Transporter 2 Inhibitor. Clinical Therapeutics, 37, 610-8.e4. https://doi.org/10.1016/j.clinthera.2014.12.013

[47] Kasichayanula, S., Liu, X., Zhang, W., Pfister, M., LaCreta, F.P. and Boulton, D.W. (2011) Influence of Hepatic Impairment on the Pharmacokinetics and Safety Profile of Dapagliflozin: An Open-Label, Parallel-Group, Single-Dose Study. Clinical Therapeutics, 33, 1798-1808. https://doi.org/10.1016/j.clinthera.2011.09.011

[48] Zhang, M., Zhang, L., Wu, B., Song, H., An, Z. and Li, S. (2014) Dapagliflozin Treatment for Type 2 Diabetes: A Systematic Review and Meta-Analysis of Randomized Controlled Trials. Diabetes/Metabolism Research and Reviews, 30, 204-221. https://doi.org/10.1002/dmrr.2479

[49] Nigro, S.C., Riche, D.M., Pheng, M. and Baker, W.L. (2013) Canagliflozin, a Novel SGLT2 Inhibitor for the Treatment of Type 2 Diabetes. Annals of Pharmacotherapy, 47, 1301-1311. https://doi.org/10.1177/1060028013503626

[50] Scheen, A.J. (2014) Pharmacokinetic and Pharmacodynamic Profile of Empagliflozin, a Sodium-Glucose Co-Transporter 2 Inhibitor. Clinical Pharmacokinetics, 53, 213-225. https://doi.org/10.1007/s40262-013-0126-X

[51] Buse, J.B., Klonoff, D.C., Nielsen, L.L., Guan, X., Bowlus, C.L., Holcombe, J.H., et al. (2007) Metabolic Effects of Two Years of Exenatide Treatment on Diabetes, Obesity, and Hepatic Biomarkers in Patients with Type 2 Diabetes: An Interim Analysis of Data from the Open-Label, Uncontrolled Extension of Three Double-Blind, Placebo-Controlled Trials. Clinical Therapeutics, 29, 139-153. https://doi.org/10.1016/j.clinthera.2007.01.015

[52] Ohki, T., Isogawa, A., Iwamoto, M., Ohsugi, M., Yoshida, H., Toda, N., et al. (2012) The Effectiveness of Liraglutide in Non-Alcoholic Fatty Liver Disease Patients with Type 2 Diabetes Mellitus Compared to Sitagliptin and Pioglitazone. Scientific World Journal, 2012, Article ID: 496453. https://doi.org/10.1100/2012/496453

[53] Tolman, K.G., Fonseca, V., Dalpiaz, A. and Tan, M.H. (2007) Spectrum of Liver Disease in Type 2 Diabetes and Management of Patients with Diabetes and Liver Disease. Diabetes Care, 30, 734-743. https://doi.org/10.2337/dc06-1539

[54] Petrides, A.S., Stanley, T., Matthews, D.E., Vogt, C., Bush, A.J. and Lambeth, H. (1998) Insulin Resistance in Cirrhosis: Prolonged Reduction of Hyperinsulinemia Normalizes Insulin Sensitivity. Hepatology, 28, 141-149.

https://doi.org/10.1002/hep.510280119

[55] Marks, V. and Teale, J.D. (1999) Drug-Induced Hypoglycemia. Endocrinology and Metabolism Clinics of North America, 28, 555-577. https://doi.org/10.1016/S0889-8529(05)70088-8

[56] Perseghin, G., Mazzaferro, V., Sereni, L.P., Regalia, E., Benedini, S., Bazzigaluppi, E., et al. (2000) Contribution of Reduced Insulin Sensitivity and Secretion to the Pathogenesis of Hepatogenous Diabetes: Effect of Liver Transplantation. Hepatology, 31, 694-703. https://doi.org/10.1002/hep.510310320 